\title{
Do respiratory symptoms predict job choices in teenagers?
}

\author{
K. Radon*, S. Huemmer*, H. Dressel*,\#, D. Windstetter*, , G. Weinmayr ${ }^{\# \text {, }}$ \\ S. Weiland ${ }^{\#}$, E. Riu*, C. Vogelberg ${ }^{+}$, W. Leupold ${ }^{+}$, E. von Mutius", \\ M. Goldberg ${ }^{\S}$ and D. Nowak*
}

ABSTRACT: Existing guidelines advise adolescents with asthma and allergies against high-risk occupations. The aim of the current authors' analyses was to investigate the resulting selfselection in a prospective cohort study.

The participants of Phase II of the International Study of Asthma and Allergies in Childhood in Germany (aged 9-11 yrs at baseline) were re-contacted after 7 yrs (response rate was $77 \%$ ) and were asked to complete a questionnaire, which included items on atopic diseases. The subjects were also asked about the type of job they would like to have in the future (preferred job choice). Exposure to agents with potential asthma risk was evaluated using a job exposure matrix. The analyses were restricted to those in school-based vocational training programmes without occupational exposures.

A total of $33 \%$ of subjects chose jobs with high asthma risk, $23 \%$ selected low asthma risk jobs and the remaining adolescents indicated jobs without known asthma risk (reference category). There were no statistically significant associations between asthma, allergic rhinitis or atopic dermatitis and selecting jobs with asthma risk. Participants with allergic rhinitis tended to select high risk jobs less frequently.

In conclusion, self-selection into low risk jobs seems to play a minor role in teenagers with asthma or allergies.

KEYWORDS: Adolescents, allergy, asthma, cohort study, vocational education

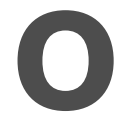

ccupational asthma is the leading cause of occupational respiratory diseases in developed countries [1]. It has been estimated that $2-36.5 \%$ of adult-onset asthma is due to occupational exposures [2]. So far, measures of primary prevention of occupational asthma, rhinitis and hand eczema where reduction of exposure is not possible are not well established [1, 3, 4]. Pre-employment selection amongst asymptomatic subjects based on atopy has been evaluated in this context $[5,6]$. Besides the ethical implications, this approach has been shown to be highly inefficient $[6,7]$.

Even less seems to be known about primary prevention of work-aggravated asthma in patients with pre-existing asthma. In a recent review, CULLINAN et al. [7] concluded that it might be reasonable to screen out those with severe or moderately severe asthma of potential employment from jobs with increased risk of exposure to asthmogens. In addition, it is recommended to thoroughly advise adolescents with asthma or allergies before they start vocational training, so as to help them select a suitable career $[7,8]$.
To date, only limited data are available on whether asthma and allergies influence career choices in adolescents [9]. Therefore, the current authors aimed to assess whether asthmatic and allergic adolescents select themselves into low risk jobs in a prospective cohort study.

\section{METHODS}

\section{Study population}

The study population consisted of the participants of Phase II of the International Study of Asthma and Allergies in Childhood (ISAAC II) in Munich and Dresden, who were enrolled in 1995 and 1996 [10]. For the follow-up study in 2002, a total of 4,893 participants were located. They each received a questionnaire along with an informed consent form; up to two reminders were also sent. Overall, 77\% of the teenagers (aged 16$18 \mathrm{yrs})$ took part in the study.

For the present study, the authors restricted the study population to vocational trainees. The reason for this was that at age 16-18 yrs high school students may have not yet thought fully about future careers. This was supported by the
AFFILIATIONS

*Institute for Occupational and Environmental Medicine, LudwigMaximilians-University, and 'Dr. von Haunersches Children's Hospital, Ludwig-MaximiliansUniversity, Munich,

\#Dept of Epidemiology, University of UIm, UIm, and

+University Children's Hospital, Carl Gustav Carus, Technical University Dresden, Dresden, Germany.

${ }^{\S}$ Dept of Medicine, McGill University Montréal, Montréal,

QC, Canada.

CORRESPONDENCE

K. Radon

Unit for Occupational and

Environmental Epidemiology \& Net

Teaching

Institute for Occupational and

Environmental Medicine

Ludwig-Maximilians-University

Munich

Ziemssenstr. 1

D-80336 Munich

Germany

Fax: 498951604954

E-mail: Katja.Radon@med.uni-

muenchen.de

Received:

August 102005

Accepted after revision:

December 212005

\section{SUPPORT STATEMENT}

This study has been supported by the German Ministry for Economy and

Labor. E. Riu has been supported by a grant from the European Respiratory Society. 
fact that only $48 \%$ of the high school students reported which job they would like to have in the future, while $79 \%$ of teenagers in vocational training programmes indicated such a job. Traditional vocational training programmes (e.g. nurses or bakers) in Germany are done on the job with only 2 days per week spent at the school. More recently vocational training, which involved full-time attendance at school accompanied by internships in different areas, became popular. The current authors restricted the study population to the latter group, assuming that they had not yet been occupationally exposed during training. In addition, subjects reporting that they had undertaken any job (e.g. holiday job), at any point, for a minimum of $8 \mathrm{~h}$ per week and for at least a 1-month period, were excluded. As shown in figure 1, 504 of the 3,785 subjects fulfilled these criteria and formed the study population for the main analyses presented in this paper.

\section{Follow-up questionnaire}

The questions were mainly taken from the European Community Respiratory Health Survey [11] and the ISAAC II questionnaire [12]. They focused on respiratory symptoms, current state of employment and the type of job subjects would like to have in the future (preferred job choice).

Each of the preferred job choices given by the participants was double coded in parallel by two well trained coders according to the International Standard Classification of Occupations code [13]. Potential exposure to specific airborne pollutants was assessed by the use of an asthma-specific job-exposure matrix (JEM) [14]. The exposures of the preferred job choices classified by the JEM were used as outcome variables. The JEM contains 22 exposure groups including 18 high risk groups, based on known risk factors for occupational asthma. These groups are divided into the following categories: high molecular weight (HMW) agents (agents derived from animals, plants, anthropods or mites, latex, flour, bioaerosols and biological enzymes); low molecular weight (LMW) agents (highly reactive chemicals, isocyanates, sensitising drugs, industrial cleaning agents, sensitising wood dusts and metal

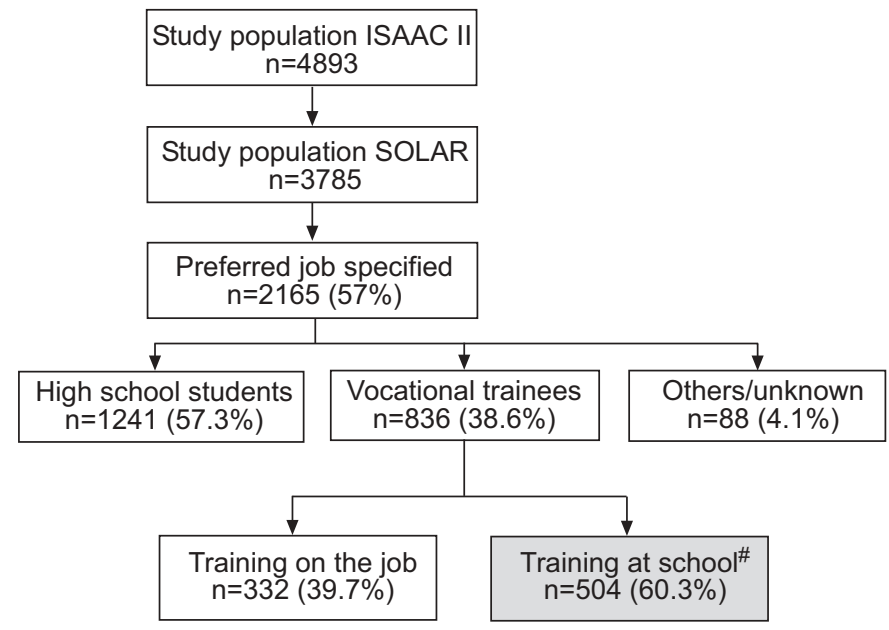

FIGURE 1. Study population included in the first follow-up of the Phase II of the International Study of Asthma and Allergies in Childhood (ISAAC II) in Munich and Dresden (Germany) and teenagers included in the analyses presented in this paper. SOLAR: Study on occupational Allergy Risks. ${ }^{*}$ : Included in the analyses. sensitisers); mixed environments (metal working fluids, agricultural environments and the textile industry); and jobs with the potential of accidental exposure to very high levels of irritants (peak exposures). In addition to these categories, one group with jobs of low asthma risk was created, which included jobs with low level exposure to chemicals or irritants, fumes and/or environmental tobacco smoke (low risk). The remaining jobs were coded as nonexposed.

For the multiple nominal regression models the following categories were used as outcome [14]: 1) Nonexposed (reference). 2) Low risk (if subject had not already been classified as high risk). 3) High risk (HMW and LMW agents, mixed environments, peak exposures). As predictors, the authors evaluated three categories of asthma, rhinitis and atopic dermatitis. These were: 1) Never: Asthma, rhinitis or atopic dermatitis never diagnosed by a doctor (reference). 2) Noncurrent: Asthma, rhinitis or atopic dermatitis ever diagnosed by a doctor (stated at baseline and/or follow-up) but no symptoms and/or use of medication during the previous 12 months. 3) Current: Asthma, rhinitis or atopic dermatitis ever diagnosed by a doctor and current symptoms.

Current asthma symptoms were defined as awakening by shortness of breath or an asthma attack during the previous 12month period, or the use of medication during the previous 12 months. Current symptoms of allergic rhinitis were considered when the participant reported a problem with sneezing, or a runny or a blocked nose without having a cold or the flu during the previous 12 months. An itchy rash during the previous 12 months was defined as current symptoms of atopic dermatitis.

\section{Statistical methods}

In order to obtain information regarding the potential selection of subjects with allergies or asthma into vocational training programmes, vocational trainees were compared with high school students. Data are presented as absolute and relative frequency. In addition, Chi-squared tests were undertaken. Age is given as mean \pm SD when comparing the two groups by unpaired t-tests.

The current authors' main interest was the association between respiratory health/atopic dermatitis and exposure related to the preferred job choice using nominal logistic regression. These analyses were restricted to vocational trainees and adjusted for sex, centre and level of schooling (9 or 10 yrs). Age was not considered a confounder because all subjects were within a limited age range (16-18 yrs).

\section{RESULTS \\ Descriptive data}

Table 1 compares vocational trainees in school-based training programmes and high school students. The data are restricted to those who indicated a preferred job choice and had never worked in a job for a minimum of $8 \mathrm{~h}$ per week and for a minimum 1-month period. Vocational trainees, when compared with high school students, were slightly older (mean $\pm \mathrm{SD}, 16.8 \pm 0.7$ versus $16.4 \pm 0.7$ yrs, respectively), more likely to be male (50 versus $44 \%$, respectively) and to live in Dresden (62 versus 44, respectively). In addition, their preferred job choice was significantly more often associated with low (23 


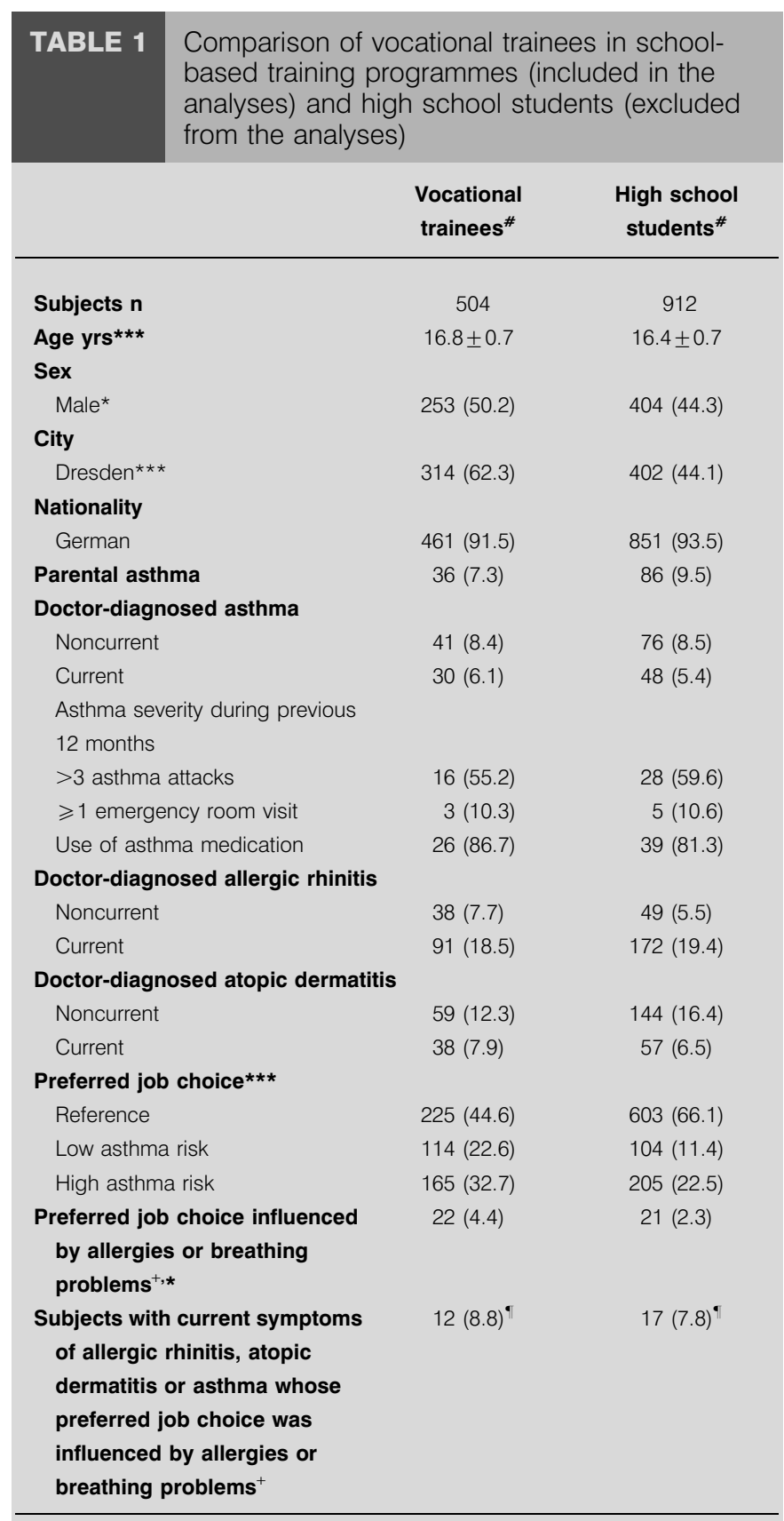

Data presented as mean \pm SD or $n(\%)$. Data numbers may not add up to the total sample size for the group due to missing data. ${ }^{\#}$ : Never had a job for $8 \mathrm{~h}$ per week, for a minimum of 1 -month and preferred job choice reported; ${ }^{+}$: based upon the response to the questionnaire item "Did/do allergies or breathing problems influence your preferred job choice?"; ": percentage of the total number of subjects with current symptoms of allergic rhinitis, atopic dermatitis or asthma ( $n=136$ vocational trainees, $n=219$ high school students). *: $p<0.05 ;{ }^{* *}: p<0.001$

versus $11 \%$, respectively) or high (33 versus $23 \%$, respectively) asthma risk, while high school students were more likely to select nonexposed jobs. The most frequent exposures of jobs with high asthma risk among vocational trainees were highly reactive chemicals $(12 \%)$, latex $(8 \%)$ and isocyanates $(6 \%)$. The dominant exposures in the low asthma risk category were irritants $(6 \%)$, motor engine exhausts (5\%) and environmental tobacco smoke ( $3 \%$; data not shown).

A total of $19 \%$ of the vocational trainees had current allergic rhinitis, $8 \%$ atopic dermatitis and $6 \%$ asthma. The prevalence of symptoms did not differ between vocational trainees and high school students. However, $4 \%$ of the vocational trainees, but only $2 \%$ of the high school students, reported that their preferred job choice was influenced by allergies or respiratory symptoms $(\mathrm{p}<0.05)$.

\section{Predictors of preferred job choice among vocational trainees}

As shown in table 2, male vocational trainees were more likely to indicate low asthma risk jobs as their preferred job choice when compared with the females in this group (odds ratio: 5.0, 95\% confidence interval 3.0-8.3). Vocational trainees with a lower level of schooling were more likely to choose jobs with high asthma risk (OR: 3.2, 95\% CI: 2.1-5.0). There was no statistically significant association between having asthma, allergic rhinitis, or atopic dermatitis and selecting jobs with asthma risk. However, teenagers with recent symptoms of allergic rhinitis tended to prefer jobs with high asthma risk less frequently than subjects without symptoms of allergic rhinitis (OR: $0.6,95 \%$ CI: $0.3-1.1$ ). These results were confirmed in the multiple regression models (table 3 ).

\section{DISCUSSION}

In the current study, vocational trainees with atopic diseases did not differ significantly in their preferred job choices from asymptomatic teenagers. If anything there was a tendency for teenagers with allergic rhinitis to avoid jobs with high risk of exposure to asthmogens.

The current study was done prospectively in a general population sample with in-depth data on childhood exposures and respiratory diseases. Therefore, the current authors could take into account the lifetime history of atopic diseases in the current study. The present authors were also able to trace most of the subjects from the ISAAC II study after $7 \mathrm{yrs}$ and obtained a high response rate. The questionnaire instruments used at baseline and follow-up have been thoroughly validated against clinical measurements [11, 12].

Only $4 \%$ of the subjects indicated that their preferred job choice had been influenced by atopic diseases. Among subjects with current symptoms of asthma, allergic rhinitis or atopic dermatitis, $8 \%$ reported that their job choice was influenced by their disease. Unfortunately, the current questionnaire did not ask whether the subjects actually had obtained professional advice in selecting their career. Therefore, the current authors were unable to determine whether this result was due to a lack of appropriate guidance given by the primary care physician or a job counselor or due to a lack of adherence to these suggestions by the teenagers. However, the prevalence of subjects who took atopic diseases into account was higher among vocational trainees than among high school students, suggesting that at least some of them had obtained advice.

While asthma and atopic dermatitis were not associated with job choices, vocational trainees with allergic rhinitis tended to avoid high risk jobs, although this association did not reach the 
TABLE 2 Relative frequency and unadjusted odds ratio (OR) with 95\% confidence intervals (Cl) for factors potentially associated with preferred job choice

\begin{tabular}{|c|c|c|c|c|c|c|}
\hline & \multicolumn{2}{|c|}{ Reference $^{\#}$} & \multicolumn{2}{|c|}{ Low asthma risk $^{+}$} & \multicolumn{2}{|c|}{ High asthma risk } \\
\hline & n (\%) & OR (95\% Cl) & n (\%) & OR (95\% Cl) & n (\%) & OR (95\% Cl) \\
\hline \multicolumn{7}{|l|}{ Sex } \\
\hline Male & $94(41.8)$ & 1 & 89 (78.1) & $4.96(2.96-8.32)$ & 70 (42.4) & $1.03(0.68-1.54)$ \\
\hline \multicolumn{7}{|l|}{ City } \\
\hline German & $204(90.7)$ & 1 & $108(94.7)$ & $1.85(0.73-4.73)$ & $149(90.3)$ & $0.96(0.48-1.90)$ \\
\hline Parental asthma & $12(5.4)$ & 1 & $9(7.9)$ & $1.49(0.61-3.66)$ & $15(9.3)$ & $1.79(0.81-3.94)$ \\
\hline Schooling $<10$ yrs & $64(28.4)$ & 1 & $44(38.9)$ & $1.60(1.00-2.58)$ & $93(56.4)$ & $3.24(2.13-4.96)$ \\
\hline \multicolumn{7}{|c|}{ Doctor-diagnosed asthma } \\
\hline Never & $187(85.4)$ & 1 & $93(84.5)$ & 1 & $140(86.4)$ & 1 \\
\hline Noncurrent & $20(9.1)$ & 1 & $10(9.1)$ & $1.01(0.45-2.24)$ & $11(6.8)$ & $0.74(0.34-1.58)$ \\
\hline \multicolumn{7}{|c|}{ Doctor-diagnosed allergic rhinitis ${ }^{\S}$} \\
\hline Current & $35(17.3)$ & 1 & $25(24.5)$ & $1.50(0.83-2.69)$ & 17 (11.6) & $0.59(0.32-1.11)$ \\
\hline \multicolumn{7}{|c|}{ Doctor-diagnosed atopic dermatitis ${ }^{\S}$} \\
\hline Never & $160(80.4)$ & 1 & $77(78.6)$ & 1 & $120(82.8)$ & 1 \\
\hline Noncurrent & $26(13.1)$ & 1 & $16(16.3)$ & $1.28(0.65-2.52)$ & $13(9.0)$ & $0.67(0.33-1.35)$ \\
\hline Current & $13(6.5)$ & 1 & $5(5.1)$ & $0.80(0.28-2.32)$ & $12(8.3)$ & $1.23(0.54-2.79)$ \\
\hline
\end{tabular}

${ }^{\#}: \mathrm{n}=225{ }^{+}: \mathrm{n}=144 ;{ }^{\bullet}: \mathrm{n}=165{ }^{\S}{ }^{\S}$ : subjects with current asthma have been excluded from these analyses $(n=30)$.

level of statistical significance. It is somewhat surprising that allergic rhinitis might influence job selection more than asthma or atopic dermatitis. One reason might be that the power, especially for asthma and atopic dermatitis, was low as the

\section{TABLE 3 Associations between respiratory symptoms and preferred job choices}

\begin{tabular}{|c|c|c|c|}
\hline & Reference & Low asthma risk & High asthma risk \\
\hline Subjects $n$ & 213 & 109 & 156 \\
\hline \multicolumn{4}{|c|}{ Doctor-diagnosed asthma } \\
\hline Never & 1 & 1 & 1 \\
\hline Noncurrent & 1 & $0.85(0.37-1.98)$ & $0.71(0.32-1.57)$ \\
\hline Current & 1 & $1.05(0.38-2.88)$ & $1.12(0.47-2.68)$ \\
\hline \multicolumn{4}{|c|}{ Doctor-diagnosed allergic rhinitis ${ }^{\#}$} \\
\hline Never & 1 & 1 & 1 \\
\hline Noncurrent & 1 & $0.49(0.18-1.36)$ & $0.45(0.18-1.13)$ \\
\hline Current & 1 & $1.42(0.76-2.65)$ & $0.57(0.30-1.10)$ \\
\hline \multicolumn{4}{|c|}{ Doctor-diagnosed atopic dermatitis ${ }^{\#}$} \\
\hline Never & 1 & 1 & 1 \\
\hline Noncurrent & 1 & $1.18(0.57-2.42)$ & $0.72(0.34-1.50)$ \\
\hline Current & 1 & $0.95(0.31-2.89)$ & $1.43(0.61-3.36)$ \\
\hline
\end{tabular}

Data are presented as odds ratios (OR) with $95 \%$ confidence intervals, both of which have been adjusted for sex, centre and level of schooling. ${ }^{\#}$ : Subjects with current asthma have been excluded from these analyses $(n=30)$. current authors restricted the study population to those in vocational training. This also limited the study population to teenagers with only 9 or 10 yrs of schooling and thus reduced the generalisation of the results. As shown in table 1, the study subjects also differed significantly from high school students with respect to sex, place of living and job choice. Repeating the current analyses with the whole study population, no association between atopic disease and potential job choice could be found (data not shown). However, due to the limited number of asthmatics in the study population, the current authors could unfortunately not take asthma severity into account.

Due to their chronic disease, asthmatics as well as young people with atopic dermatitis have been shown to reach lower levels of schooling than expected based on their level of intelligence $[4,15]$. Therefore, the range of available job choices for asthmatics is reduced not only by potential exposure in their preferred jobs but also by their level of schooling [16]. This might contribute to the observation that adolescents with asthma or atopic dermatitis do not take potential adverse health effects into account in their job choice [16]. Nevertheless, the lifetime history of allergic rhinitis, asthma and atopic dermatitis did not differ between vocational trainees and high school students.

Overall, the health-based selection into specific jobs seems to be small in the study population. This might indicate a need for improved advice, especially directed to adolescents with asthma, regarding the potential health risks associated with 
their future job, enabling them to make a more informed choice concerning their future careers.

\section{ACKNOWLEDGEMENTS}

The authors would like to thank C. Janßen (Institute for Occupational and Environmental Medicine, Ludwig-Maximilians University, Munich, Germany) for the job coding, and the subjects for their participation. Parts of this paper have been used for the medical thesis of S. Huemmer (Institute for Occupational and Environmental Medicine, Ludwig-Maximilians University, Munich, Germany).

\section{REFERENCES}

1 Curran AD, Fishwick D. Occupational asthma: research, change and the 30\% target. Ann Occup Hyg 2003; 47: 433-436.

2 Blanc PD, Toren K. How much adult asthma can be attributed to occupational factors? Am J Med 1999; 107: 580-587.

3 Hellgren J, Karlsson G, Toren K. The dilemma of occupational rhinitis: management options. Am J Respir Crit Care Med 2003; 2: 333-341.

4 Lapidus CS, Kerr PE, Bieber T, et al. Socioeconomic impact of atopic dermatitis. In: Bieber T, Leung YM, eds. Atopic Dermatitis. New York, NY, USA, Marcel Dekker, 2002; pp. 67.

5 Hendrick DJ. Management of occupational asthma. Eur Respir J 1994; 7: 961-968.

6 Chan-Yeung M. Occupational asthma. Environ Health Perspect 1995; 103: Suppl. 6, 249-252.

7 Cullinan P, Tarlo S, Nemery B. The prevention of occupational asthma. Eur Respir J 2003; 22: 853-860.
8 Walusiak J, Palczynski C, Hanke W, et al. The risk factors of occupational hypersensitivity in apprentice bakers-the predictive value of atopy markers. Int Arch Occup Environ Health 2002; 75: Suppl., S117-121.

9 Martin AJ, Landau LI, Phelan PD. Asthma from childhood at age 21: the patient and his disease. Br Med J (Clin Res Ed) 1982; 284: 380-382.

10 Weiland SK, von Mutius E, Hirsch T, et al. Prevalence of respiratory and atopic disorders among children in the East and West of Germany five years after unification. Eur Respir J 1999; 14: 862-870.

11 Burney P. Ten years of research on asthma in Europe. The European Community Respiratory Health Survey. Rev Epidemiol Sante Publique 1998; 46: 491-496.

12 Asher MI, Keil U, Anderson HR, et al. International Study of Asthma and Allergies in Childhood (ISAAC): rationale and methods. Eur Respir J 1995; 8: 483-491.

13 International Labour Office S. International Standard Classification of Occupations (ISCO-88). Geneva, ILO Publications, 1991.

14 Kennedy SM, Le Moual N, Choudat D, et al. Development of an asthma specific job exposure matrix and its application in the epidemiological study of genetics and environment in asthma (EGEA). Chest 2000; 57: 635-641.

15 Dorsch U, Lecheler J. [Preventive vocational measures for adolescents with asthma and allergies - a model project.] Pneumologie 1990; 44: 905-908.

16 Ueberschar I. [In the chosen occupation health must also play a part! An analysis of occupational medicine assessment of adolescents with health handicaps.] Gesundheitswesen 2001; 63: 162-165. 